\title{
Part III. Molecular changes induced by high nitric oxide adaptation in human breast cancer cell line BT-20 (BT-20-HNO): a switch from aerobic to anaerobic metabolism
}

\author{
H. De Vitto • B. S. Mendonça • K. M. Elseth • A. Onul • \\ J. Xue • B. J. Vesper • C. V. M. Gallo • F. D. Rumjanek • \\ W. A. Paradise • J. A. Radosevich
}

Received: 27 June 2012 / Accepted: 15 October 2012 / Published online: 14 December 2012

(C) International Society of Oncology and BioMarkers (ISOBM) 2012

\begin{abstract}
Nutrient deprivation and reactive oxygen species (ROS) play an important role in breast cancer mitochondrial adaptation. Adaptations to these conditions allow cells to survive in the stressful microenvironment of the tumor bed. This study is directed at defining the consequences of High Nitric Oxide (HNO) exposure to mitochondria in human breast cancer cells. The breast cancer cell line BT-20 (parent) was adapted to $\mathrm{HNO}$ as previously reported, resulting in the BT-20-HNO cell line. Both cell lines were analyzed by a variety of methods including MTT, LDH leakage assay, DNA sequencing, and Western blot analysis. The LDH assay and the gene chip data
\end{abstract}

\author{
H. De Vitto • B. S. Mendonça • F. D. Rumjanek \\ Universidade Federal do Rio de Janeiro, IBqM, \\ Rio de Janeiro, Brazil \\ H. De Vitto $\cdot$ K. M. Elseth $\cdot$ A. Onul $\cdot$ J. Xue $\cdot$ B. J. Vesper $\cdot$ \\ W. A. Paradise $\cdot$ J. A. Radosevich $(\triangle)$ \\ Center for Molecular Biology of Oral Diseases, \\ College of Dentistry, University of Illinois at Chicago, \\ 801 S. Paulina St., \\ Chicago, IL 60612, USA \\ e-mail: jrados@uic.edu \\ H. De Vitto $\cdot$ K. M. Elseth $\cdot$ A. Onul $\cdot$ J. Xue $\cdot$ B. J. Vesper $\cdot$ \\ W. A. Paradise $\cdot$ J. A. Radosevich \\ Jesse Brown VAMC, \\ Chicago, IL, USA \\ H. De Vitto - K. M. Elseth • A. Onul · J. Xue • B. J. Vesper \\ W. A. Paradise $\cdot$ J. A. Radosevich \\ Department of Oral Medicine and Diagnostic Sciences, \\ College of Dentistry, University of Illinois at Chicago, \\ Chicago, IL, USA \\ C. V. M. Gallo \\ Universidade do Estado do Rio de Janeiro, IB, DECB, \\ Rio de Janeiro, Brazil
}

showed that BT-20-HNO was more prone to use the glycolytic pathway than the parent cell line. The BT-20-HNO cells were also more resistant to the apoptotic inducing agent salinomycin, which suggests that p53 may be mutated in these cells. Polymerase chain reaction (PCR) followed by DNA sequencing of the $p 53$ gene showed that it was, in fact, mutated at the DNA-binding site (L194F). Western blot analysis showed that p53 was significantly upregulated in these cells. These results suggest that free radicals, such as nitric oxide (NO), pressure human breast tumor cells to acquire an aggressive phenotype and resistance to apoptosis. These data collectively provide a mechanism by which the dysregulation of ROS in the mitochondria of breast cancer cells can result in DNA damage.

Keywords Breast cancer $\cdot$ Nitric oxide $\cdot \mathrm{p} 53 \cdot$ Reactive oxygen species (ROS) · Glycolysis and apoptosis · Aerobic and anaerobic metabolisms

\section{Introduction}

Breast cancer continues to be the most prevalent neoplastic disease among women and a leading cause of death among cancers in women [1]. It has been proposed that cancer outcomes are the result of variations in the microenvironment, which is a driving force in the clonal selection of cells with genetic and metabolic alterations resulting in angiogenesis, invasion, and metastasis [2, 3]. Reactive oxygen species (ROS) and reactive nitrogen species (RNS), such as hydrogen peroxide $\left(\mathrm{H}_{2} \mathrm{O}_{2}\right)$ and nitric oxide $(\mathrm{NO})$, when present in high concentration and prolonged stimulus have been implicated in the pathophysiology of cancer as agents that alter cell homeostasis $[4,5]$. 
The free radical NO plays an important role in both normal and human tumor cell biology. NO in low concentrations is known to have benign, modulating, and regulatory effects on normal mammalian and human biology. Higher concentrations of NO have been shown to be both damaging and pathologic to physiologic processes resulting in mutational events which might lead to cancer and promote progression of the tumor [6-8]. Our laboratory and others have shown that $\mathrm{NO}$ is overexpressed in many human cancers [9]. Additionally, in in vitro experiments, we have demonstrated that different cancer types such as lung [10], breast [11], and head and neck [12] may be adapted gradually to high concentrations of NO. Over an approximately 100-day period, the original 'parental' human breast tumor cell line BT-20 was adapted to a comparatively high dose of $\mathrm{NO}$ (that is lethal to the parent cell line) to generate a new adapted cell line, BT-20-High Nitric Oxide (HNO). After the adaptation process, two important results were observed in the BT-20-HNO: (1) the cell line grew faster and (2) was more aggressive than the parent cell line [11]. These same results were also observed with long-term $\mathrm{H}_{2} \mathrm{O}_{2}$ exposure in the lung cancer cell line A549-HHP [13]. This prior work suggested that the ROS may shift the metabolism of adapted cells to be prone to anaerobic metabolism, a hallmark of an aggressive cancer phenotype.

Mitochondria are organelles where the cell combines hydrogen and oxygen to generate the major molecular source of energy, adenosine triphosphate (ATP) [14]. As toxic byproducts of oxidative phosphorylation (OXPHOS) activity, mitochondria generate ROS. These have been extensively characterized in the literature to signal tumor growth $[15$, 16]. The tumor suppressor protein, $\mathrm{p} 53$, plays an important role in mitochondria which includes involvement in the process of mtDNA repair and replication [17]. The p53 protein also induces the expression of many nuclear genes involved in ROS homeostasis and apoptosis [5].

This study characterizes the current state of knowledge regarding the molecular and cellular mechanisms by which NO contribute to breast cancer progression. Herein, using a number of key cellular and molecular techniques such as MTT, LDH leakage assay, DNA sequencing, and Western blot analysis, we explored the ROS-p53-mitochondrial interrelationship in a breast tumor cell line model system. Our results suggest that free radicals, such as NO, pressure human breast tumor cells to acquire an aggressive phenotype with more glycolytic metabolism and resistance to apoptosis.

\section{Material and methods}

Cell culture and cell lines

The media and all supplements were purchased from Invitrogen (CA, USA), except where noted. The BT-20 human breast tumor cell line [18] was purchased from the American Type Culture Collection (VI, USA) and was grown in Minimal Essential Media (MEM). The MEM media was supplemented with $10 \%$ fetal calf serum inactivated at $56{ }^{\circ} \mathrm{C}$ for $30 \mathrm{~min}, 100 \mathrm{U} / \mathrm{mL}$ penicillin, $100 \mu \mathrm{g} / \mathrm{mL}$ streptomycin, $2 \mathrm{mML}$-glutamine, and $2.5 \mu \mathrm{g} / \mathrm{mL}$ Amphotericin B solution. Furthermore, it was supplemented with $100 \mathrm{mM}$ MEM nonessential amino acids and $1 \mathrm{mM}$ sodium pyruvate (Cellgro, Inc., VI, USA). The BT-20 cell line was grown in a humidified incubator at $37{ }^{\circ} \mathrm{C}$ and $5 \% \mathrm{CO}_{2}$. The BT-20$\mathrm{HNO}$ cell line was prepared via long-term adaptation to high concentrations of the nitric oxide donor (Z)-1-[2-(2-aminoethyl)- $N$-(2-amminoethyl) amino] diazen-1-ium-1,2-diolate (DETA-NONOate; Sigma-Aldrich, St. Louis, MO, USA) and maintained as previously described [11].

Measurement of cell viability

Cell viability was carried out based on measurement of (3[4,5-dimethylthiazol-2-yl]-2,5-diphenyltetrazolium bromide) MTT assay, as previously reported [19]. Parent and HNO cells were seeded into 96-well microtiter plates with $100 \mu \mathrm{L}$ of the appropriate MEM media (i.e., adapted cells were seeded in the presence of $600 \mu \mathrm{M}$ DETA-NONOate) and allowed to establish overnight to $60 \%$ confluency. Following exposure to NO donor, the media was removed from all wells and both cells were treated with $100 \mu \mathrm{L}$ of media containing three different conditions: (1) levels of 2deoxy-D-glucose (2-DOG) ranging from 0.02 to $12 \mu \mathrm{M}$, (2) levels of rotenone ranging from 0.001 to $1 \mu \mathrm{M}$, and (3) both inhibitors together, 2-DOG and rotenone, in ten serial dilutions ranging from 0.02 to $12 \mu \mathrm{M}$ for 2-DOG and 0.001 to $1 \mu \mathrm{M}$ for rotenone. Cell data were collected at $24 \mathrm{~h}$ and $48 \mathrm{~h}$ after being treated. Furthermore, cell viability was carried out with treatment of different levels of salinomycin ranging from 0.39 to $100 \mu \mathrm{M}$. These results were collected at $48 \mathrm{~h}$ and $72 \mathrm{~h}$ after treatment.

After the incubation period, media were removed from each well and $100 \mu \mathrm{L}$ of $2 \mathrm{mg} / \mathrm{mL}$ of MTT was added (Sigma-Aldrich, MO, USA) and phosphate-buffered saline (PBS) was then added to each well. Plates were incubated at $37{ }^{\circ} \mathrm{C}$ for $4 \mathrm{~h}$. The MTT solution was then removed, leaving purple formazan crystals which were subsequently dissolved in $100 \mu \mathrm{L}$ of dimethylsulfoxide. The absorbance of each well was then read at $540 \mathrm{~nm}$ using a SpectraMax ${ }^{\circledR}$ Plus384 spectrophotometer (Molecular Devices, CA, USA).

Measurement of cell cytotoxicity

The BT-20 and BT-20-HNO cell line cytotoxicity activity was determined based on measurement of lactate dehydogenase activity in the extracellular media using the $\mathrm{LDH}$ 
leakage assay [20]. Parent and HNO cells were seeded into 96-well microtiter plates in $100 \mu \mathrm{L}$ of the MEM media (i.e., adapted cells were seeded in the presence of $600 \mu \mathrm{M}$ DETA-NONOate) and allowed to establish overnight to $60 \%$ confluency. The media was then removed from all wells and $100 \mu \mathrm{L}$ of appropriate media without phenol red was used to replenish the wells. Both cell types were treated with $100 \mu \mathrm{L}$ of media containing 2-DOG $(0.1 \mu \mathrm{M})$, rotenone $(0.01 \mu \mathrm{M})$, or both inhibitors together. Data were collected at $24 \mathrm{~h}$ and $48 \mathrm{~h}$ after seeding. The activity of LDH was measured using a commercially available kit (CytoTox $96^{\circledR}$ NonRadioactive Cytotoxicity Assay; Promega, WI, USA) and used according to the manufacturer's protocol. The absorbance of each well was then read at $490 \mathrm{~nm}$ using a SpectraMax ${ }^{\circledR}$ Plus384 spectrophotometer (Molecular Devices, CA, USA).

Mutation analysis of TP53 gene

We analyzed the TP53 gene by directly sequencing the DNA in the BT-20 human breast tumor cell line parent and HNO according to the International Agency for Research on Cancer (IARC) TP53 database [21]. Total DNA extraction of the BT20 parent and BT-20-HNO cell lines were performed as previously described [22]. Thirteen DNA fragments of the TP53 gene ranging in size from $177 \mathrm{bp}$ to $467 \mathrm{bp}$ were generated by polymerase chain reaction (PCR) amplification (Table 1).

PCR was performed according to the IARC protocol, 2010 update, for 50 cycles in a $20 \mu \mathrm{L}$ reaction mixture containing 50-300 ng DNA, $200 \mu \mathrm{M}$ of each dNTP, $0.4 \mu \mathrm{M}$ of each primer, $1.5 \mathrm{mM} \mathrm{MgCl} 2,0.5 \mathrm{U}$ of Taq DNA polymerase recombination (Invitrogen, Inc.), and $4 \mu \mathrm{L}$ of $1 \times$ PCR Rxn buffer (Invitrogen, Inc.). PCR was performed in an ABI GeneAmp PCR System 9700 DNA thermal cycler (Applied Biosystems, CA, USA) according the IARC protocol (2010 update). The PCR products were purified by enzymatic assay with Exonuclease I, E. coli plus phosphatase alkaline (GE Healthcare, WI, USA) and sequenced with an ABI Big Dye Terminator (version 3.1) cycle sequencing ready reaction kit and an ABI PRISM 3130 sequencer (Applied Biosystems, Foster City, CA, USA) according to the manufacturer's recommendation.
Table 1 Nucleotide sequences of the primers

\begin{tabular}{|c|c|c|c|}
\hline DNA fragment & Primer sequence $\left(5^{\prime} \rightarrow 3^{\prime}\right)$ & Nucleotide position & Product length (bp) \\
\hline 1 & Exons 2-3 & $\begin{array}{l}\text { TCTCATGCTGGATCCCCACT } \\
\text { AGTCAGAGGACCAGGTCCTC }\end{array}$ & 344 \\
\hline 2 & Exon 4 & $\begin{array}{l}\text { TGCTCTTTTCACCCATCTAC } \\
\text { ATACGGCCAGGCATTGAAGT }\end{array}$ & 353 \\
\hline 3 & Exon 4 & $\begin{array}{l}\text { TGAGGACCTGGTCCTCTGAC } \\
\text { AGAGGAATCCCAAAGTTCCA }\end{array}$ & 413 \\
\hline 4 & Exon 5 & $\begin{array}{l}\text { TTCAACTCTGTCTCCTTCCT } \\
\text { CAGCCCTGTCGTCTCTCCAG }\end{array}$ & 248 \\
\hline 5 & Exon 6 & $\begin{array}{l}\text { GCCTCTGATTCCTCACTGAT } \\
\text { TTAACCCCTCCTCCCAGAGA }\end{array}$ & 181 \\
\hline 6 & Exons 5-6 & $\begin{array}{l}\text { TGTTCACTTGTGCCCTGACT } \\
\text { TTAACCCCTCCTCCCAGAGA }\end{array}$ & 467 \\
\hline 7 & Exon 7 & $\begin{array}{l}\text { CTTGCCACAGGTCTCCCCAA } \\
\text { AGGGGTCAGAGGCAAGCAGA }\end{array}$ & 237 \\
\hline 8 & Exon 7 & $\begin{array}{l}\text { AGGCGCACTGGCCTCATCTT } \\
\text { TGTGCAGGGTGGCAAGTGGC }\end{array}$ & 177 \\
\hline 9 & Exon 8 & $\begin{array}{l}\text { TTCCTTACTGCCTCTTGCTT } \\
\text { AGGCATAACTGCACCCTTGG }\end{array}$ & 231 \\
\hline 10 & Exons 8-9 & $\begin{array}{l}\text { TTGGGAGTAGATGGAGCCT } \\
\text { AGTGTTAGACTGGAAACTTT }\end{array}$ & 445 \\
\hline 11 & Exon 9 & $\begin{array}{l}\text { GACAAGAAGCGGTGGAG } \\
\text { CGGCATTTTGAGTGTTAGAC }\end{array}$ & 215 \\
\hline 12 & Exon 10 & $\begin{array}{l}\text { CAATTGTAACTTGAACCATC } \\
\text { GGATGAGAATGGAATCCTAT }\end{array}$ & 260 \\
\hline 13 & Exon 11 & $\begin{array}{l}\text { AGACCCTCTCACTCATGTGA } \\
\text { TGACGCACACCTATTGCAAG }\end{array}$ & 245 \\
\hline
\end{tabular}

Core of primers used to sequence and real-time PCR 
Both forward and reverse DNA strands were used for DNA sequencing and resequencing again to confirm the mutations within each DNA fragment. DNA fragments from BT-20 parent and HNO cell lines were analyzed. When compared with the TP53 sequence of BT-20 parent cell line, any DNA sequence differences of the parent and the HNO cell lines were scored as somatic mutations. Both DNA fragments from both breast tumor cell lines (parent and HNO) were compared with the TP53 sequence gene [21], and any DNA sequence differences of both cell lines were scored as a polymorphism.

Immunoblotting of cell line samples

Western blots were prepared as previously reported [23]. In brief, we determined expression levels of p53 in the BT-20 parent and HNO cell lines. Cell lysates were made by suspending cells in $1 \times$ SDS sample buffer solution $(62.5 \mathrm{mM}$ Tris-HCl, pH 6.8, 2 \% SDS, $10 \%$ glycerol, 50 mM DTT, and $0.01 \%$ bromophenol blue). SDS-PAGE was used to separate the proteins followed by electrophoretic transfer to a nitrocellulose membrane. Nonspecific binding was blocked by using $5 \%$ nonfat dry milk in TBST $(10 \mathrm{mM}$ Tris- $\mathrm{HCl}, \mathrm{pH} 7.5$, $0.15 \mathrm{M} \mathrm{NaCl}$, and $0.05 \%$ Tween 20), kept overnight at $4{ }^{\circ} \mathrm{C}$. After incubation with anti-p53 antibody (Thermo Fisher Scientific, Inc., MA, USA; Catalog \#P53 ab-8), the blots were incubated in TBST containing $5 \%$ nonfat dry milk for $2 \mathrm{~h}$ at $22{ }^{\circ} \mathrm{C}$. The membranes were washed with TBST and incubated, alternately with horseradish peroxidase-conjugated goat anti-mouse secondary antibody or horseradish peroxidase-conjugated goat anti-rabbit secondary antibody for $1 \mathrm{~h}$, depending on the primary antibody used. After washing the membranes, protein bands were visualized using enhanced chemiluminescent substrate (Thermo Fisher Scientific, Inc., Waltham, MA, USA, SuperSignal West Pico Chemiluminescent Substrate). $\beta$-Actin was used as a control and the expression level was normalized against the $p 53$ gene target. It should be noted that both the mutant and wild type forms of p53 interact with the anti-p53 antibody.

\section{Gene chip analysis}

Gene chip analysis was carried out as described in Part I of this series of the three manuscripts [25].

Data analysis and statistics

At least three independent experiments were conducted for each experiment type. The statistical analysis and data were performed using SigmaPlot version 11.0 (Systat Software, Inc., Chicago, IL, USA). The statistical analyses were calculated by using the two-tailed Student's $t$ tests assuming equal variance.

\section{Results}

Cell viability, glycolysis level production, and acid resistance

We previously validated the BT-20 parent/HNO cell line model system as a means to study ROS damage in mitochondrial DNA (mtDNA) [8]. Herein, we studied the molecular and cellular characterizations of the human breast cancer cell line BT-20 adapted to long-term HNO exposure. To determine if free radicals like NO might be able to force BT-20-HNO cells to switch in the metabolism profile from OXPHOS to "aerobic glycolysis" as proposed in the literature [25-27], we carried out cell viability MTT assay with 2-DOG and rotenone. These are two inhibitors of the glycolytic pathway and mitochondrial complex I activity [28]. Our results showed that after $24 \mathrm{~h}$ and $48 \mathrm{~h}$ of treatment with high concentrations of 2DOG ranging from 6 and $12 \mu \mathrm{M}$, BT-20-HNO showed less proliferation versus the parent cell line, suggesting the importance of the glycolysis pathway for BT-20-HNO cells to survive (Fig. 1). The viability curve using rotenone, a mitochondrial complex I inhibitor, showed the plasticity of BT-20-HNO cells by using mitochondrial activity to produced energy after $24 \mathrm{~h}$, even though it harbored mtDNA damage (Fig. 1). Reinforcing this idea, BT-20-HNO grew faster than the parent cell line when treated with both inhibitors together after $48 \mathrm{~h}$ (Fig. 1c).

The hypothesis that BT-20-HNO was more prone to use the glycolytic pathway than the parent cell line was evidenced in Fig. 2 and Table 2. Using the LDH leakage assay, we measured lactate dehydrogenase activity in the extracellular media. The quantification of lactate as the last product of glycolysis is an indicator of glycolytic levels and cell toxicity. After $24 \mathrm{~h}$ and $48 \mathrm{~h}$ of treatment with both inhibitors, 2-DOG at $0.01 \mu \mathrm{M}$ and rotenone at $0.001 \mu \mathrm{M}$, BT-20-HNO cells showed a significant increase of cell toxicity over parent cells. This data suggested that BT20HNO, under stressful conditions, used a glycolytic pathway and was more acid resistant than the parent cell line. The gene chip analysis showed in Table 2 confirmed that the BT20-HNO cell line was more glycolytic than the 'parent' cell line (see "Gene chip analysis"). Prior work reported presumptive evidence of a conferred selective growth advantage for these tumor cells [26, 29].

Resistant to the apoptotic inducing agent salinomycin

Salinomycin has been shown to inhibit breast cancer growth and metastasis in mice, resulting in a capability to induce apoptosis in cancer cell [30]. Using the viability assay (MTT) to measure cell survival, levels of salinomycin ranging from 0.39 to $100 \mu \mathrm{M}$ were tested on the BT-20 and BT20-HNO. The data demonstrated that BT-20-HNO showed 

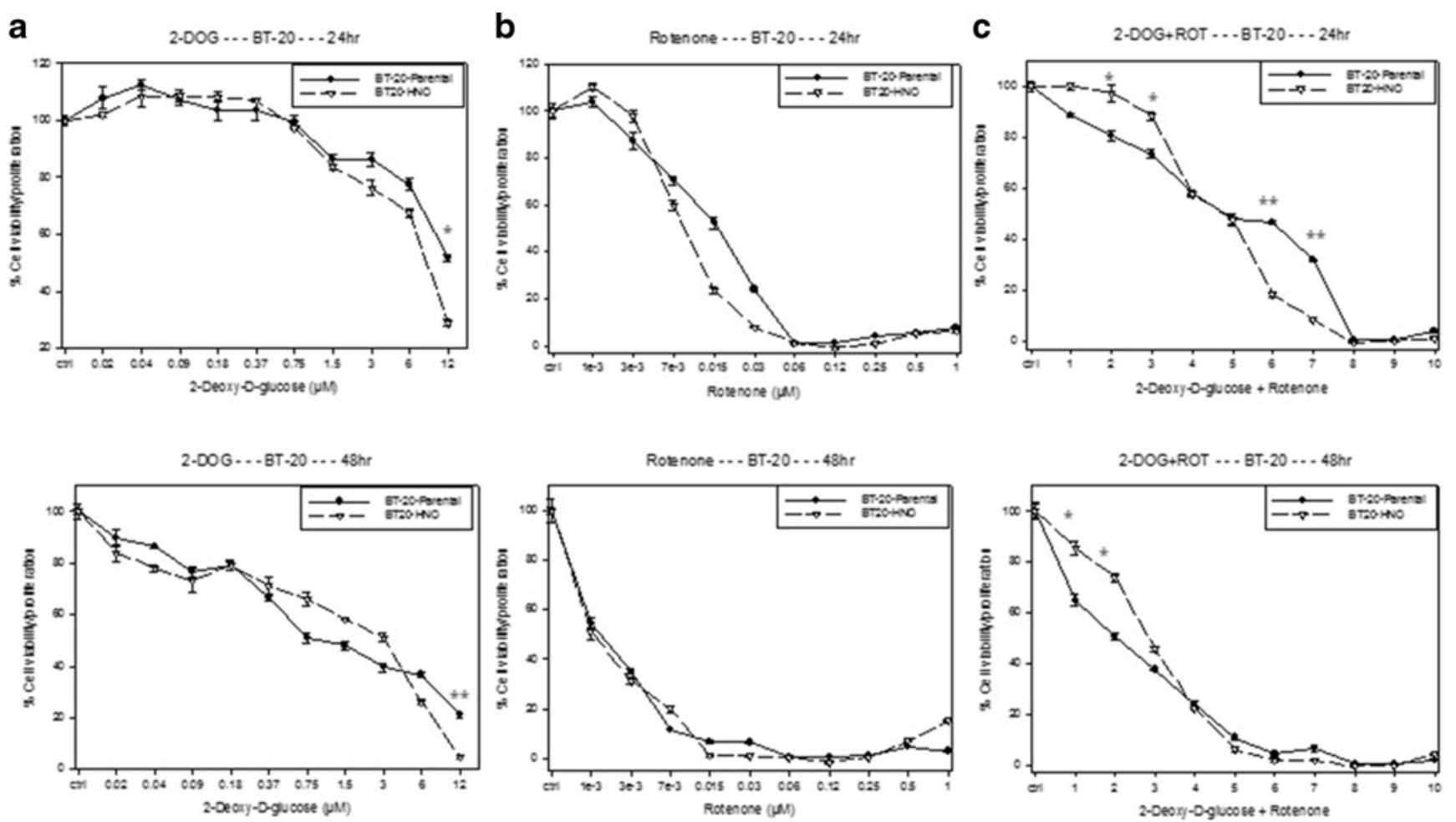

Fig. 1 Cell viability curves of BT-20 parent and HNO breast tumor cell lines. The MTT proliferation/viability curves of BT-20 parent/ HNO to varying concentrations of 2-deoxy-D-glucose (2-DOG),

rotenone, and both inhibitors together after $24 \mathrm{~h}$ and $48 \mathrm{~h}$. Data are presented as mean normalized absorbance \pm standard error $(n=5)$. ${ }^{*} P<0.05$ versus parent cells, ${ }^{* *} P<0.01$ versus parent cells

more proliferation versus the parent cell line at $48 \mathrm{~h}$ and $72 \mathrm{~h}$ (Fig. 3). The purpose of this experiment was to verify that HNO cells had a growth advantage over their corresponding parent cells, which correlated with apoptotic resistance. As shown in Fig. 3, BT-20-HNO had a significant increase in viability relative to the parent cell line. These data indicate BT-20-HNO cells are more resistant to apoptosis. The HNO

LDH_BT-20_24h

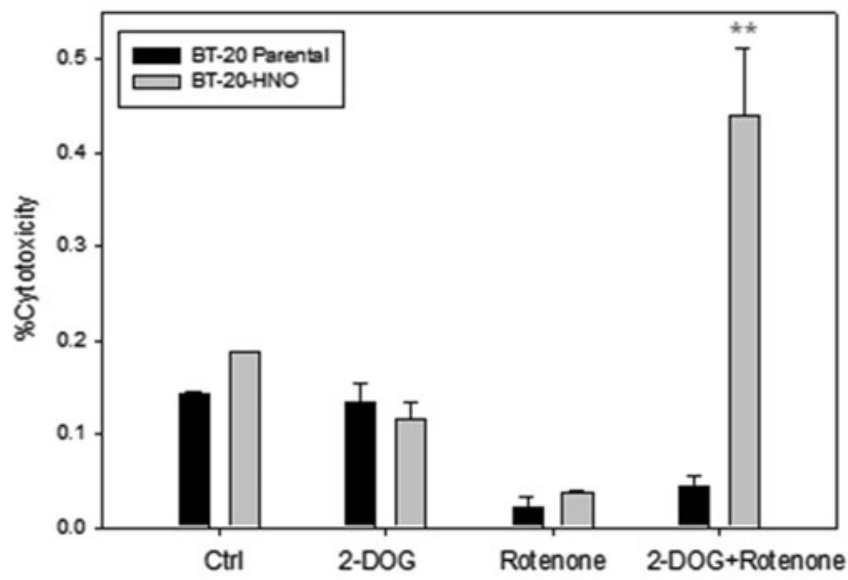

Fig. 2 Lactate dehydrogenase assays of BT-20 parent and HNO breast tumor cell lines. After exposure to $0.1 \mu \mathrm{M}$ of 2-deoxy-D-glucose (2DOG) and $0.01 \mu \mathrm{M}$ of rotenone and both inhibitors together for $24 \mathrm{~h}$ and $48 \mathrm{~h}, \mathrm{BT}-20-\mathrm{HNO}$ cell line showed more acidosis resistance and cells might do this through a p53 mechanism thereby maintaining a redox homeostasis (see below) [31, 32].

Somatic mutations in TP53 gene

The tumor suppressor protein, p53, acts to maintain cell homeostasis, such as in response to DNA damage and other

LDH_BT-20_48h

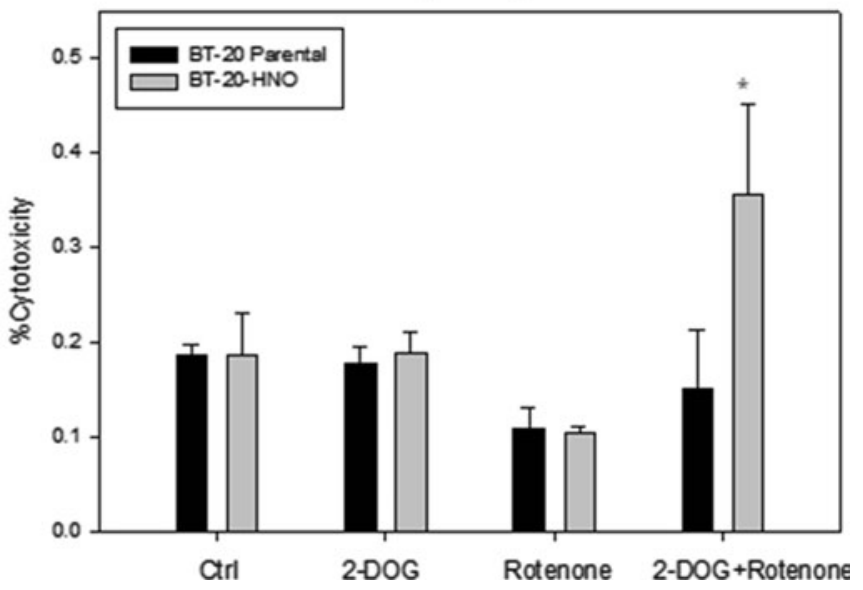

was more prone to use glycolysis. Data are presented as mean normalized absorbance \pm standard error $(n=5) .{ }^{*} P<0.05$ versus parent cells, ${ }^{* *} P<0.01$ versus parent cells 
Table 2 Gene chip results comparing the BT-20-HNO-adapted cell line relative to the BT-20 parent cell line. The first six upregulated genes are related the glycolytic pathway and are rated based on fold changes. The seven downregulated genes are related to the Krebs cycle and pentose phosphate pathways. This set of data suggests an increase in glucose metabolism occurs in the BT-20-HNO cell line relative to the BT-20 parent cell line

\begin{tabular}{lllll}
\hline GenBank ID & Gene symbol & Fold change & $P$ value & Gene description \\
\hline NM_002467 & MYC & 2.20 & 0.002 & Myc proto-oncogene protein (c-Myc) \\
NA & LDHA & 1.98 & 0.001 & Lactate dehydrogenase A \\
NM_018290 & PGM2 & 1.80 & 0.002 & Glucose phosphomutase 2 \\
NM_000188 & HK1 & 1.64 & 0.003 & Hexokinase type I \\
NM_001024939 & SLC2A11 & 1.57 & 0.003 & Glucose transporter type 11 \\
NM_016399 & TRIAP1 & 1.55 & 0.003 & p53-inducible cell-survival factor \\
NM_000402 & G6PD & -1.77 & 0.001 & Glucose-6-phosphate 1-dehydrogenase \\
NM_006755 & TALDO1 & -1.68 & 0.0009 & Transaldolase \\
NM_001096 & ACLY & -1.62 & 0.007 & ATP-citrate synthase \\
NM_001098 & ACO2 & -1.56 & 0.004 & Aconitate hydratase \\
NM_000284 & PDHA1 & -1.54 & 0.003 & Pyruvate dehydrogenase E1 subunit alpha \\
NM_003849 & SUCLG1 & -1.45 & 0.005 & Succinyl-CoA ligase \\
NM_001135055 & TKT & -1.40 & 0.006 & Transketolase \\
\hline
\end{tabular}

cellular stressful conditions [33]. In breast cancer, p53 mutations are associated with poor prognosis, and several studies have reported an association with poor response to different types of chemotherapy drugs [34]. Wild type p53 has been reported to modulate mitochondrial respiration, as well as enhancing apoptosis. It also suppresses mtDNA mutagenesis and regulates mtDNA copy number [35-37]. To determine the fidelity of the TP53 gene, we used direct DNA sequencing of the parent/HNO cell lines. As shown in the Fig. 4, one somatic mutation on exon 6 of the $p 53$ gene was indentified exclusively in the BT-20-HNO cells. This mutation occurred in a DNA-binding site of p53 protein that changed an amino acid from leucine to phenylalanine. The L194F point mutation has been reported as a somatic mutation in 27 tumors and as a germline mutation in families with Li-Fraumeni syndromes [21]. Somatic mutation in the

\section{BT20/ Salinomycin/48hr}

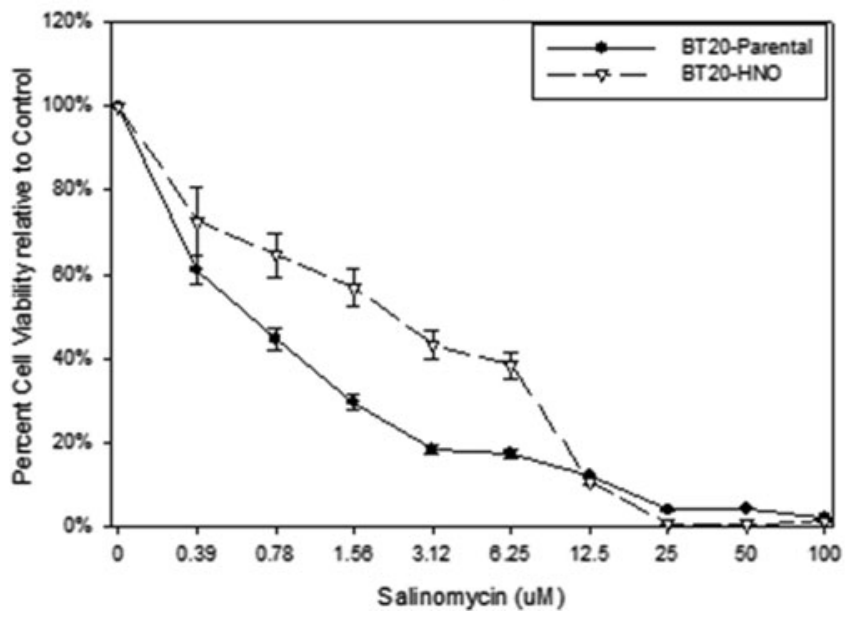

Fig. 3 Salinomycin treatments of BT-20 parent and HNO breast tumor cells. The MTT proliferation/viability curves of BT-20 parent/HNO to varying concentrations of salinomycin after $48 \mathrm{~h}$ and $72 \mathrm{~h}$. Data are p53 gene provides a clue as to the mechanism in which BT20 cell evolved after HNO exposure. HNO affects mtDNA damage, decreases mtDNA copy numbers, and changes the glycolytic profile, which allows the cells to acquire acid and apoptosis resistance.

\section{Expression level of p53}

To determine if the somatic mutation in BT-20-HNO cells affected the expression level of p53, we performed Western blot analysis on the parent/BT-20-HNO cell lines. Interestingly, the result demonstrated a significant increase (approximately threefold) in the p53 protein levels in the BT-20HNO cells versus parent cell line (Fig. 5). These data suggest that the mutational event generated a positive feedback loop in an attempt to restore $\mathrm{p} 53$ protein activity.

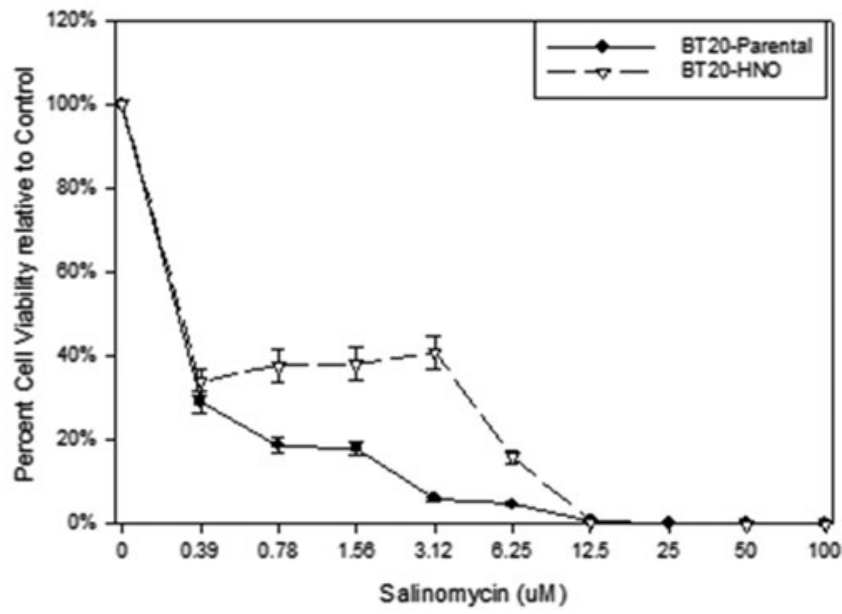

presented as mean normalized absorbance \pm standard error $(n=5) .{ }^{*} P<0.05$ versus parent cells, ${ }^{* *} P<0.01$ versus parent cells 
Fig. 4 p53 gene somatic mutations in the breast tumor cell lines. Using direct sequencing method described in "Material and Methods", the C 12649 T mutation was detected in the BT-20-HNO breast tumor cell line. The mutation caused a substitution of an amino acid residue from leucine $(\mathrm{L})$ to phenylalanine (F) in exon 6 of $p 53$ gene
BT-20_TP53_(12649C $\rightarrow$ C/T)
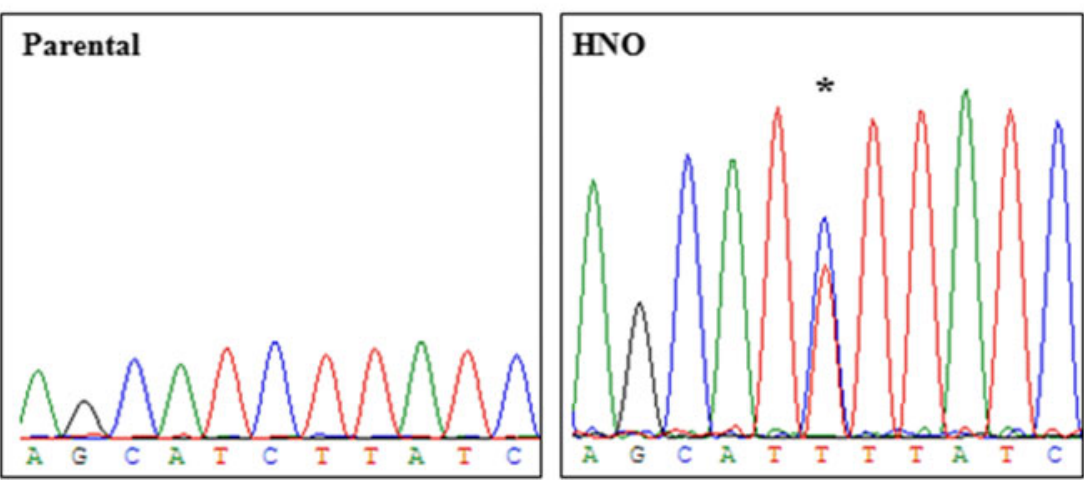

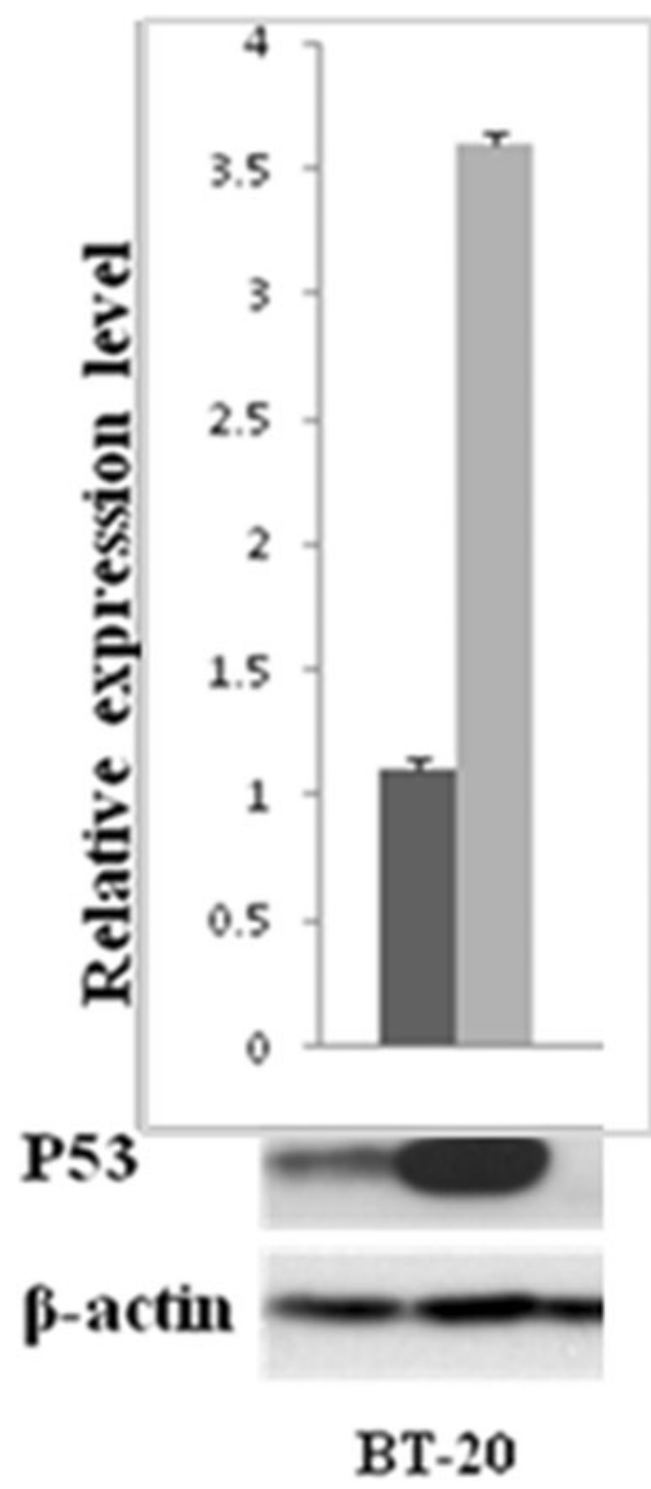

Fig. 5 Western blot analysis of p53 expression of BT-20 parent and HNO human breast tumor cell lines. The graph represents an increased level of enzyme p53 in the BT-20-HNO cell lines (approximately threefold). Data are presented as the average relative expression level \pm standard error $(n=3)$
Gene chip analysis

The results of the gene chip analysis as it relates to metabolism is outlined in Table 2. In brief, MYC, LDHA, PGM2, HK1, SLC2A11, and TRIAP1 were found to be upregulated, while G6PD, TALDO1, ACLY, ACO2, PDHA1, SUCLG1, and TKT were downregulated. Figure 7 shows a schematic of how these genes are related to both anaerobic and aerobic metabolisms. The changes in expression of these genes support the idea that HNO adaptation shifts the cell from aerobic to anaerobic metabolism and is consistent with our results reported herein.

\section{Discussion}

It is believed that free radicals such as NO play a significant role in human physiology and pathophysiology of tumor cell biology [4, 38]. In mammalian cells, there are three tissue specific isoforms of NOS: endothelial constitutive NOS (eNOS), inducible NOS (iNOS), and neuronal NOS (nNOS), all of which have been reported to be upregulated in a variety of human tumors. In breast cancer, iNOS overexpression was found to correlate with a low survival rate [39]. In order to understand the underlying mechanism of human breast cancer in the clinical setting and the role of NO, we adapted BT-20 to NO to produce BT-20-HNO and other breast cell lines [11]. These cell lines provide a model system in which we can understand the molecular mechanisms involved to become adapted to NO. In addition, we have adapted a number of tumor cell line pairs arising from other anatomical sites [9, $13,40,41]$ and have studied both cell line pairs using a number of cellular and molecular methods including: MTT viability assay, FACS, LDH leakage assay, DNA sequencing, DNA fragments cloning, qPCR, and Western blot analysis.

As reported by us in the paper submitted in conjunction with the current manuscript [8], the BT-20-HNO cell line harbored somatic mtDNA mutation in the NADH dehydrogenase gene and in the mitochondrial replication site of mitochondrial genome. These results, together with the previously 
reported decrease of mtDNA copy number of the HNO cells, when compared with the parent cells, suggests a mitochondrial "malignancy" in the tumor cell [8]. Previous works have linked mtDNA damage with cancer development, progression, and metastasis [40, 41]. Studies using cytoplasmic hybrid (cybrid) technology to replace the endogenous mtDNA with another mtDNA mutant have shown that the mitochondrial genome damage might be associated with ROS production, apoptosis resistance, and increased metastasis [42, 43]. Our results were consistent with these findings in that after long-term adaption to high concentrations of NO, the BT-20HNO was more prone to use the glycolytic pathway than the parent cell line. At the higher concentrations of 2-DOG used in this study (ranging from 6 and $12 \mu \mathrm{M}$ ), BT-20-HNO showed less proliferation versus the parent cell line, suggesting the importance of the glycolysis pathway for BT-20-HNO cells to survive (Fig. 1). Furthermore, BT-20-HNO grew faster than the parent cell line when treated with both inhibitors together after $48 \mathrm{~h}$ (Fig. 1). In addition, after $24 \mathrm{~h}$ and $48 \mathrm{~h}$ of treatment with both inhibitors (2-DOG at $0.01 \mu \mathrm{M}$ and rotenone at $0.001 \mu \mathrm{M}$ ), BT-20-HNO cells showed a significant increase in cell toxicity compared to the parent cell line (Fig. 2). This result suggests that the BT-20-HNO may be correlated with phenotypes resistant to acid-induced cell toxicity. Together, the glycolysis profile and acid resistance provide a powerful growth advantage, which promotes unconstrained proliferation and invasion [26].

Salinomycin is an apoptosis-inducing agent with increasing application in cancer therapy. As reported by Gupta et al., salinomycin can inhibit breast tumor growth in mice [44]. Herein, we analyzed cell viability using the MTT assay of both BT-20 cell lines to different salinomycin concentrations. The results show that BT-20-HNO cells were significantly more proliferative versus the parent cell line at $48 \mathrm{~h}$ and $72 \mathrm{~h}$ (Fig. 4). In breast cancer, p53 mutations are associated with poor prognosis and several studies have

\section{Mitochondrial mechanism in breast cancer cell line.}

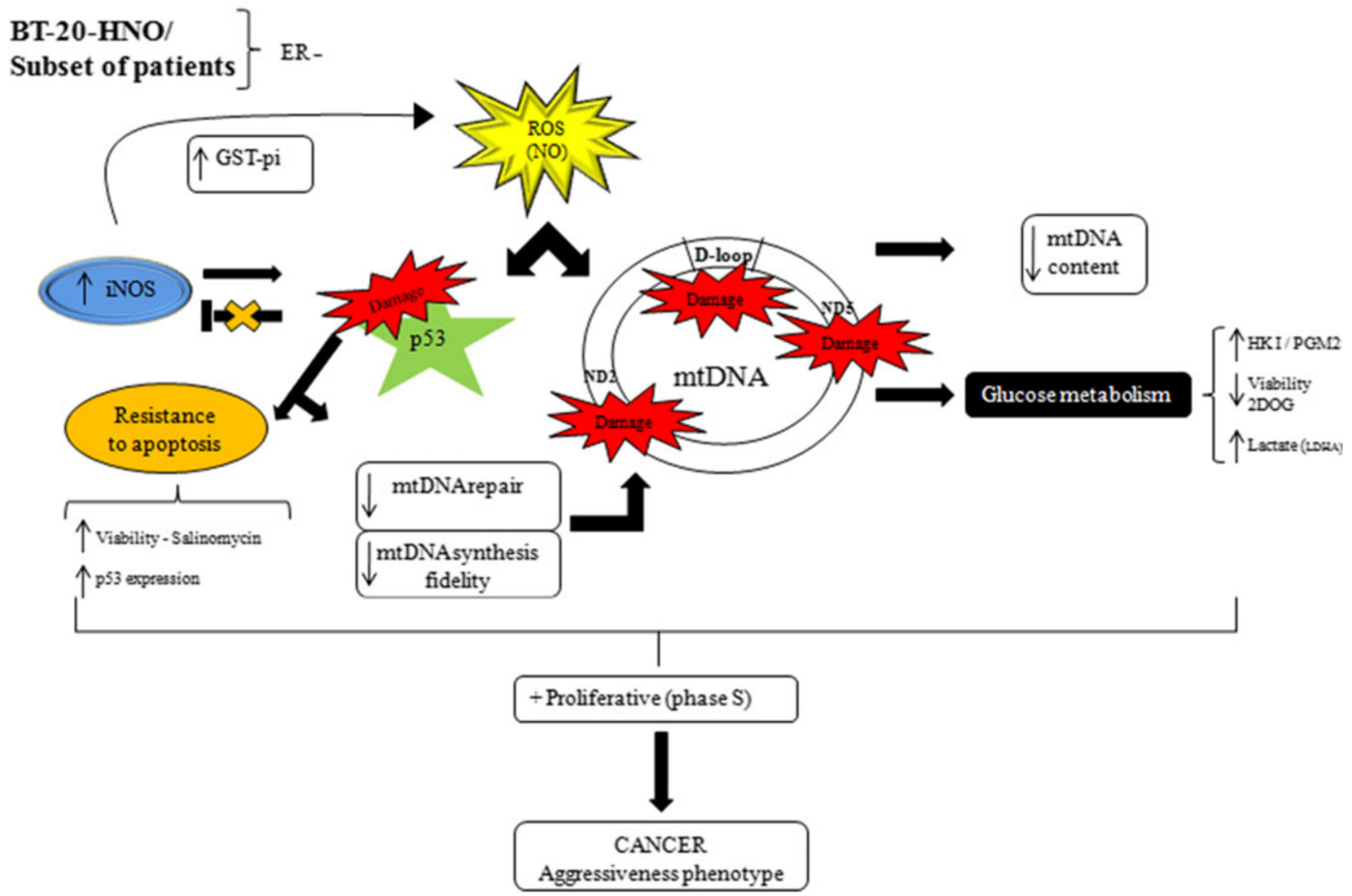

Fig. 6 Schematic representations of the ROS-p53 interrelationship with mitochondrial "malignancy." Nitric oxide (NO) stimulates mitochondrial damage and a metabolic switch of the BT-20-HNO tumor cell line to become more prone to use glycolysis. Furthermore, the BT20 -HNO cell line grew faster and was more acidosis resistant than the parent cells. The $p 53$ gene is involved in the process of mtDNA repair and replication and was mutated in the BT-20-HNO cell line, which results in mtDNA mutations and a decrease in the mtDNA copy number. A positive feedback loop attempts to upregulate p53 involved in ROS homeostasis and apoptosis 
reported an association with a poor response to different types of chemotherapy drugs [34]. These results together support the idea that a p53-dependent mechanism is involved in the BT-20-HNO tumor cell adaptation to NO.

The TP53 gene DNA sequence was analyzed for both BT20 parent and the HNO cell lines. One somatic point mutation was identified on exon 6 of the TP53 gene exclusively in the BT-20-HNO cells (Fig. 4). This mutation occurred in a DNAbinding site of the p53 protein that changed an amino acid from leucine to phenylalanine. The L194F point mutation has been reported as a somatic mutation in 27 tumors as a germline mutation in families with Li-Fraumeni syndromes [21]. In additional, the p53 enzyme activity was significantly upregulated in these cells (Fig. 5).

Our results suggest that free radicals, such as NO, pressure human breast tumor cells to acquire an aggressive phenotype which harbored somatic mutations in nuclear DNA and mtDNA. This consequentially results in a more proliferative, more prone to use glycolysis, more resistance to apoptosis and acidosis cell phenotype. In Fig. 6 we showed a schematic
Fig. 7 Anaerobic metabolism of the BT-20-HNO cells. The schematic shows some of the relevant aspects of the metabolism of glucose. After entering the cell by transport, glucose can be utilized by glycolysis to generate pyruvate and other metabolic intermediates. Herein, the pentose phosphate pathway is downregulated, represented by the G6PD and TKTL genes being inhibited (see Table 2). In the cytoplasm, the generated pyruvate can be reduced to lactate and further exported from the cell or oxidized in the mitochondria by pyruvate dehydrogenase to generate acetyl-CoA. Herein, the upregulation of LDHA, PDHA1, and Myc suggests that pyruvate is reduced to lactate. Furthermore, down regulation of genes involved in the Krebs cycle, such as ACLY, ACO2, and SCULD1, confirm the anaerobic metabolism of the BT20-HNO cells

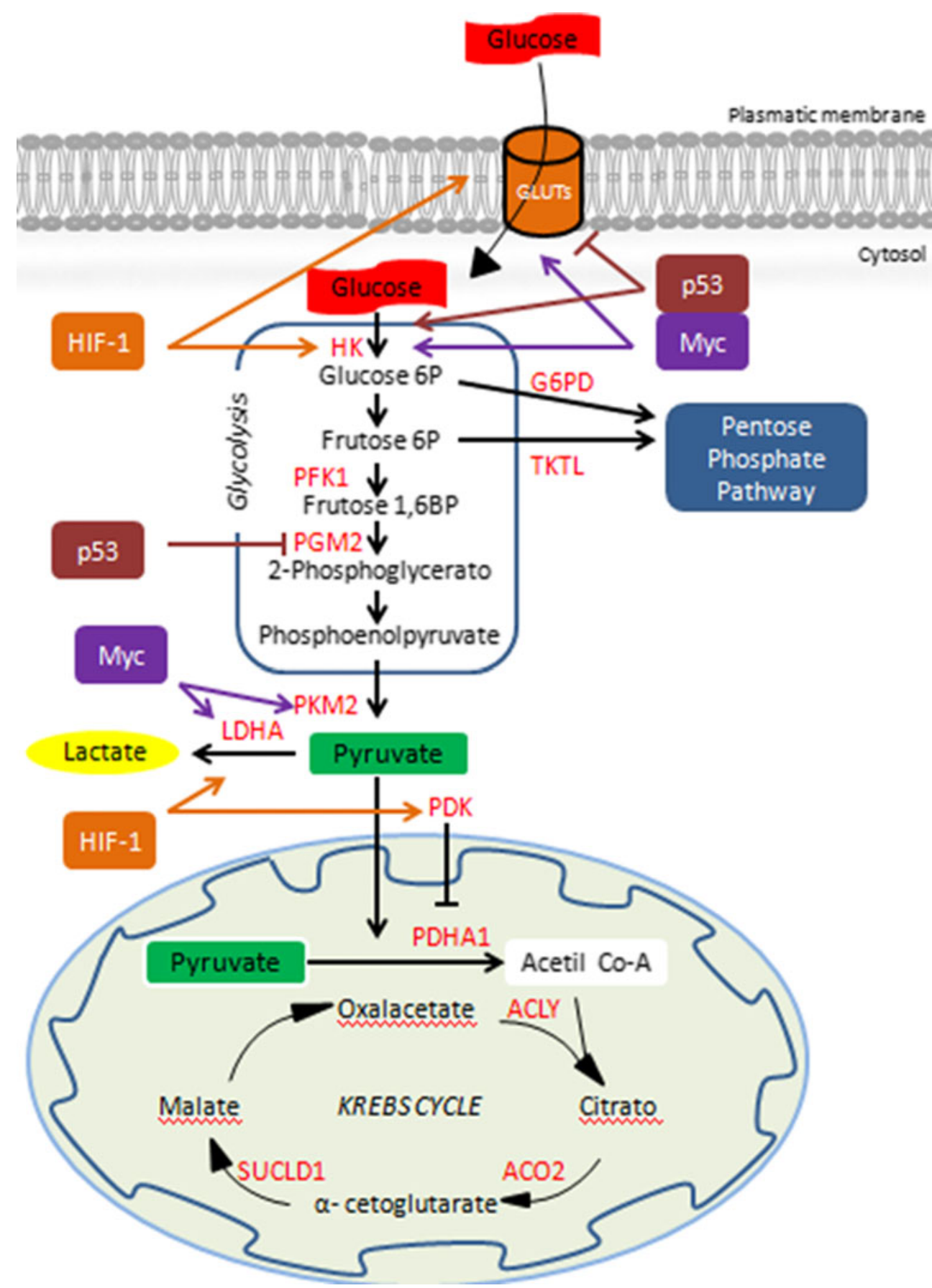


representation of a mechanism using ROS-p53-mitochondria "malignancy," which was indentified after the adaptation process with NO in the BT-20-HNO tumor cell transformation.

According to Switzer et al., NO production in cancer cells might be regulated by an NOS2- and p53-depedent mechanism. Wild type p53 antagonizes NOS2 via two mechanisms. p53 can bind in the promoter region of the NOS2 gene and inhibit expression or $\mathrm{p} 53$ has been shown to bind to the NOS2 protein and inhibit NOS activity. NO stabilizes p53, leading to apoptosis. However, cells require wild type p53 to induce apoptosis, since NO does not drive the apoptosis process in p53 null cells. The authors suggested that $\mathrm{p} 53$ status plays a significant role in determining the pro- or antitumorigenic roles of NO in cancer cells [45].

NO is a natural product produced by all human cells tested to date. The reports of human tumors overexpressing $\mathrm{NO}$ are, therefore, not surprising. It is the correlation of outcomes with the spectrum of NO expression that is intriguing, with NO production linked to poor outcome. In order to understand how NO influences outcomes, we produced breast cancer and other cancer cell lines that were adapted to comparatively high levels of NO that resemble levels noted in clinic samples. These adapted cell lines have many molecular and cellular properties that are seen clinically and give us a window into how patient tumors may adapt to the treatments they are given.

The gene chip data reported herein supports the other findings regarding the shift of the BT-20-HNO cells from aerobic to anaerobic metabolism (Table 2; Fig. 7). This is consistent with what is known about tumors as they progress in the clinical setting and suggest that $\mathrm{NO}$ is the responsible agent for this switch.

Knowing that the model system accurately reflects the clinical setting is important, but we are still faced with significant challenges. First, we need to determine what starts the tumor cells to begin producing increased levels of NO, thereby producing the spectrum of expression noted in the clinical setting. The understanding of what starts this progression would be important to understand as it would result in how cancer patients are treated. Another challenge is to find way to reverse the increased expression of NO. Yet another challenge is to determine how current treatments, many of which work through a free radical mechanism, influence the expression of $\mathrm{NO}$ in tumors. As reported herein and in the related manuscripts, we now have the tools to undertake these studies.

\section{References}

1. Siegel R, et al. Cancer statistics, 2011: the impact of eliminating socioeconomic and racial disparities on premature cancer deaths. CA Cancer J Clin. 2011;61(4):212-36.
2. Moller P, et al. Air pollution, oxidative damage to DNA, and carcinogenesis. Cancer Lett. 2008;266(1):84-97.

3. Semenza GL. Defining the role of hypoxia-inducible factor 1 in cancer biology and therapeutics. Oncogene. 2010;29(5):625-34.

4. Paradise WA, et al. Nitric oxide: perspectives and emerging studies of a well known cytotoxin. Int J Mol Sci. 2010;11 (7):2715-45.

5. Ralph SJ, et al. The causes of cancer revisited: "mitochondrial malignancy" and ROS-induced oncogenic transformation - why mitochondria are targets for cancer therapy. Mol Aspects Med. 2010;31(2):145-70.

6. Jenkins DC, et al. Roles of nitric oxide in tumor growth. Proc Natl Acad Sci USA. 1995;92(10):4392-6.

7. Bentz BG, et al. The yin and yang of nitric oxide: reflections on the physiology and pathophysiology of NO. Head Neck. 2000;22 (1):71-83.

8. De Vitto H, Mendonça BS, Elseth KM, et. al. Part II. Mitochondrial mutational status of high nitric oxide adapted cell line BT-20 (BT-20$\mathrm{HNO}$ ) as it relates to human primary breast tumors (submitted in conjunction with current manuscript). Tumor Biol. 2012. doi:10.1007/s13277-012-0555-4.

9. Bentz BG, et al. Nitric oxide synthase type 3 is increased in squamous hyperplasia, dysplasia, and squamous cell carcinoma of the head and neck. Ann Otol Rhinol Laryngol. 1999;108 (8):781-7.

10. Radosevich JA, Elseth KM, Vesper BJ, et al. Long-term adaptation of lung tumor cell lines with increasing concentrations of nitric oxide donor. Open Lung Canc J. 2009;2:35-44.

11. Vesper BJ, et al. Long-term adaptation of breast tumor cell lines to high concentrations of nitric oxide. Tumor Biol. 2010;31(4):267-75.

12. Yarmolyuk YR, et al. Part I. Development of a model system for studying nitric oxide in tumors: high nitric oxide-adapted head and neck squamous cell carcinoma cell lines. Tumor Biol. 2011;32 (1):77-85.

13. Onul A, et al. Long-term adaptation of the human lung tumor cell line A549 to increasing concentrations of hydrogen peroxide. Tumor Biol. 2012; 33(3):739-48.

14. Scudellari M. Does mitochondrial dysfunction lie at the heart of common, complex diseases like cancer and autism? The Scientist. 2011;25:30-5.

15. Nelson DA, et al. Hypoxia and defective apoptosis drive genomic instability and tumorigenesis. Genes Dev. 2004;18(17):2095-107.

16. Samper E, et al. Increase in mitochondrial biogenesis, oxidative stress, and glycolysis in murine lymphomas. Free Radic Biol Med. 2009;46(3):387-96.

17. Wong TS, et al. Physical and functional interactions between human mitochondrial single-stranded DNA-binding protein and tumour suppressor p53. Nucleic Acids Res. 2009;37(2):568-81.

18. Lasfargues EY, Ozzello L. Cultivation of human breast carcinomas. J Natl Cancer Inst. 1958;21(6):1131-47.

19. Mossmann T. Rapid colorimetric assay for cellular growth and survival: application to proliferation and cytotoxicity assays. J Immunol Meth. 1983;65:55-63.

20. Decker T, Lohmann-Matthes ML. A quick and simple method for the quantitation of lactate dehydrogenase release in measurements of cellular cytotoxicity and tumor necrosis factor (TNF) activity. J Immunol Methods. 1988;115(1):61-9.

21. Petitjean A, et al. Impact of mutant p53 functional properties on TP53 mutation patterns and tumor phenotype: lessons from recent developments in the IARC TP53 database. Hum Mutat. 2007;28(6):622-9.

22. Blin N, Stafford DW. A general method for isolation of high molecular weight DNA from eukaryotes. Nucleic Acids Res. 1976;3(9):2303-8.

23. Cubillos-Rojas M, et al. Simultaneous electrophoretic analysis of proteins of very high and low molecular mass using tris-acetate polyacrylamide gels. Electrophoresis. 2010;31(8):1318-21. 
24. Vesper BJ, et al. Part I. Molecular and cellular characterization of high nitric oxide-adapted human breast adenocarcinoma cell line. Tumor Biol. doi:10.1007/s13277-012-0530-0.

25. Warburg O. On respiratory impairment in cancer cells. Science. 1956;124(3215):269-70.

26. Gatenby RA, Gillies RJ. Why do cancers have high aerobic glycolysis? Nat Rev Cancer. 2004;4(11):891-9.

27. Semenza GL. HIF-1: upstream and downstream of cancer metabolism. Curr Opin Genet Dev. 2010;20(1):51-6.

28. Rodriguez-Enriquez $\mathrm{S}$, et al. Targeting of cancer energy metabolism. Mol Nutr Food Res. 2009;53(1):29-48.

29. Secomb TW, et al. Theoretical simulation of oxygen transport to tumors by three-dimensional networks of microvessels. Adv Exp Med Biol. 1998;454:629-34.

30. Fuchs D, et al. Salinomycin induces apoptosis and overcomes apoptosis resistance in human cancer cells. Biochem Biophys Res Commun. 2009;390(3):743-9.

31. Sablina AA, et al. The antioxidant function of the p53 tumor suppressor. Nat Med. 2005;11(12):1306-13.

32. Kim KY, et al. Salinomycin-induced apoptosis of human prostate cancer cells due to accumulated reactive oxygen species and mitochondrial membrane depolarization. Biochem Biophys Res Commun. 2011;413(1):80-6.

33. Levine AJ, Momand J, Finlay CA. The p53 tumour suppressor gene. Nature. 1991;351(6326):453-6.

34. Olivier M, Hainaut P, Borresen-Dale A. Prognostic and predictive value of TP53 mutations in human cancer, in 25 years of p53 research. In: Hainaut P, Wiman K, editors. Springer; 2005.

35. Tomita Y, et al. WT p53, but not tumor-derived mutants, bind to $\mathrm{Bcl} 2$ via the DNA binding domain and induce mitochondrial permeabilization. J Biol Chem. 2006;281 (13):8600-6.

36. Hagn $\mathrm{F}$, et al. BclxL changes conformation upon binding to wildtype but not mutant p53 DNA binding domain. J Biol Chem. 2010;285(5):3439-50.

37. Achanta G, et al. Novel role of p53 in maintaining mitochondrial genetic stability through interaction with DNA Pol gamma. EMBO J. 2005;24(19):3482-92.

38. Nathan C, Xie QW. Nitric oxide synthases: roles, tolls, and controls. Cell. 1994;78(6):915-8.

39. Loibl S, et al. The role of early expression of inducible nitric oxide synthase in human breast cancer. Eur J Cancer. 2005;41(2):26571.

40. Chatterjee A, Mambo E, Sindransky D. Mitochondrial DNA mutations in human cancer. Oncogene. 2006;25:4663-74.

41. Lu J, Sharma LK, Bai Y. Implications of mitochondrial DNA mutations and mitochondrial dysfunction in tumorigenesis. Cell Res. 2009;19(7):802-15.

42. Ishikawa K, Takenaga K, Akimoto M, et al. ROS-generating mitochondrial DNA mutations can regulate tumor cell metastasis. Science. 2008;320:661-4.

43. Kulawiec M, Owens KM, Singh KK. mtDNA G10398A variant in African-American women with breast cancer provides resistance to apoptosis and promotes metastasis in mice. J Hum Genet. 2009;54 (11):647-54.

44. Gupta PB, et al. Identification of selective inhibitors of cancer stem cells by high-throughput screening. Cell. 2009;138 (4):645-59.

45. Switzer $\mathrm{CH}$, et al. Nitric oxide and protein phosphatase $2 \mathrm{~A}$ provide novel therapeutic opportunities in ER-negative breast cancer. Trends Pharmacol Sci. 2011;32(11):644-51. 